\title{
Inhibitory Action of 1-phenyl-3-methylpyrazol-5-one (HPMP) and 1-phenyl-3-methyl-4-(p-nitrobenzoyl)- pyrazol-5-one (HPMNP) on the Corrosion of Alpha and Beta Brass in HCl Solution
}

\author{
C. I. Akabueze ${ }^{1}$, A. U. Itodo ${ }^{2, *}$ \\ ${ }^{1}$ Department of Pure and Applied Chemistry, Usmanu Danfodiyo University, Sokoto, Nigeria \\ ${ }^{2}$ Department of Applied Chemistry, Kebbi State University of Science and Technology, Aliero, Nigeria
}

\begin{abstract}
The inhibition of corrosion of Alpha - Brass ( $70 \% \mathrm{Cu}, 30 \% \mathrm{Zn})$ coupons and Beta - Brass (60\% Cu, $40 \% \mathrm{Zn})$ coupons in different concentrations of Hydrochloric acid solution $(\mathrm{HCl})$ at room temperature by 1-phenyl-3- methylpyrazol5- one (HPMP) and 1-phenyl-3-methyl-4-(p-Nitrobenzoyl)-pyrazol-5-one (HPMNP) was investigated, using weight loss technique. Generally, inhibition was found to increase with increasing inhibitor concentration. HPMNP inhibited the two Brasses better than HPMP, and Beta - Brass ( $60 \% \mathrm{Cu}, 40 \% \mathrm{Zn})$ corroded faster than Alpha - Brass ( $70 \% \mathrm{Cu}, 30 \% \mathrm{Zn})$. The inhibition was assumed to occur via adsorption of the inhibitor molecules on the metal surface. The effect of immersion time was also carefully followed to study the corrosion and inhibition phenomenon.
\end{abstract}

Keywords Corrosion, Brass, 1-Phenyl-3-methylpyrazol-5-one, 1-phenyl-3-methyl-4-(p-Nitrobenzoyl)-pyrazol-5-one, Inhibitor, Mild steel

\section{Introduction}

Brasses are alloy of copper and zinc. It has been used extensively for many years in a variety of corrosive environment. Its corrosion is a universal environmental problem, as it affects all aspects of industries. This problem has led many chemists (scientists) to sort out the causes and solutions to this corrosive problem.

The increasing interest in the manufacture and use of Hydrochloric acid $(\mathrm{HCl})$, and the fact that some parts of ship are made of Brass, have created the need for obtaining information on the corrosion resistance of Brass in this acid.

The corrosion rates of metals can be determined by using different electrochemical and non - electrochemical techniques, but in this investigation, Weight Loss Technique was used. In this work, the acid corrosion resistant ability of Brass has been studied, with and without the presence of 1phenyl-3-methylpyrazol-5-one (HPMP) and 1-phenyl-3methyl-4-(p-Nitrobenzoyl)-pyrazol-5-one (HPMNP). Corrosion is defined as the destructive attack of a metal or alloy by the environment [1].

Environment includes atmospheres, sea - water, etc.

* Corresponding author:

Itodoson2002@gmail.com (A.U. Itodo)

Published online at http://journal.sapub.org/chemistry

Copyright (C) 2012 Scientific \& Academic Publishing. All Rights Reserved corrosion can also be defined as the tearing away, e.g. of a metal, by an acid.

It is a process of spontaneous destruction of metals under the influence of the environment. It is a surface phenomenon. It is the interaction between a material and its environment, resulting in a degradation of the properties of that material [2].

The prime motive for research in corrosion is its economic factors. The losses sustained by industries amount to several millions of Naira. The economic losses are divided into:

(i) Direct losses and (ii) Indirect losses.

Direct losses are due to the cost of replacing corroded structures and machinery or their components, such as metal roofing, pipelines and condenser tubes. Cost also includes labour demand by their maintenance.

Assessing the indirect losses is a different task, but nevertheless, they make their contribution towards the impact of corrosion on the economy. Examples of indirect losses are as follows: (i) Loss of Product: Losses of water, oil or gas that is born by a corroded pipe until its detection and repairs are effected. Gas leaking from a corroded pipe, on entering the basement of a building, may lead to pressure build - up, which may result in the collapse of the building. (ii) Shut Down: Factory or one of its units can be shutdown in order to repair that which was brought about by corrosion, thereby slowing the rate of production, which may cost some hundreds of Naira per hour. 
Corrosion can bring about the following: (a). A poor or unacceptable appearance; (b). Failure in the structure of a metal; (c). Contamination of products, such as food; (d). Health problems, and (e). Loss of valuable materials.

All these and many other reasons suggest why corrosion studies (and its monitoring) are indispensable.

Corrosion is classified into Low - Temperature and High - Temperature Corrosion. There are also Direct Combination (or Oxidation) and Electrochemical Corrosion. Another classification which is preferred by Corrosion Engineers is Wet and Dry Corrosion [3].

Wet Corrosion occurs when a liquid is present. It usually involves aqueous solutions or electrolytes, and accounts for the greatest amount of corrosion.

Dry Corrosion occurs in the absence of a liquid phase or above the dew point of the environment. It is mostly often associated with high temperature.

Broadly, two types of corrosion exists; viz - Uniform and Localized Corrosion.

Uniform Corrosion is the least insidious among the corrosion types. It occurs when an Electro-chemical reaction takes place uniformly over the entire surface of a metal. In this case, Anodic and cathodic areas are inseparable. Localized Corrosion is characterized by regions of locally severe corrosion, although the general loss of thickness may be relatively small. If the localized corrosion is confined to a specific area, it is called Pitting. Other examples of localized corrosion include Galvanic Stress and Hydrogen Em-brittlement Corrosion.

Factors Affecting Corrosion include:- (i). Mass Transport:- Corrosion is strongly influenced by the rate of reagents to the metallic surface and the rate of removal of reaction products from the same surface. This is so because accumulation of insoluble corrosion products on the surface of the metal will stifle corrosion reaction in such regions. (ii). Temperature:- Rate of corrosion increases with rise in temperature. Solution of the same concentration, out with higher temperature may be Anodic to the one with lower temperature and hence have more corrosion tendency. Temperature has a secondary effect which is through its influence on the solubility of oxygen $\left(\mathrm{O}_{2}\right)$ in aqueous solutions. Oxygen is the most common oxidizing substance which drives corrosion reactions. Its absence in a corroding system may reduce the corrosion of the metal. (iii). Film Uniformity:- All films are not uniform. There are weak points called Flams in films. The progress of corrosion is sometimes controlled by the nature of the film that may form or accumulate on the metallic surface. Films that are not continuous may lead to localized corrosion in particular areas, or to induced - accelerated corrosion to certain point by initiating electrolytic effect of the concentration cell type. (iv). Purity of the Corrodent:- Impurities in a corrosive environment can either be advantageous and / or disadvantageous from the corrosion stand - point. An impurity may promote corrosion or act as an inhibitor. (v). Erosion:- This is a factor that influence corrosion. Many confuse erosion for corrosion. Corrosion is the deterioration of a substances or its property by its environment, while Erosion is the physical washing away of films that cover the surface of a metal. Increased erosion increases corrosion, and this type of corrosion which is brought about by erosion may be termed Erosion Corrosion.

Certain alloys of importance in commerce, such as the $\mathrm{Cu}$ - $\mathrm{Zn}$ alloys (Brass) contain a reactive metal $(\mathrm{Zn})$ and a more noble metal $(\mathrm{Cu})$. Upon exposure to a particularly corrosive environment, the Brass becomes covered with a reddish film, suggesting that Zinc has gone into the solution, and the copper remained behind. Actually, both elements dissolve and copper is re-deposited to form the reddish - appearing surface. This process of losing zinc from the alloy, (Brass), leaving a porous mass of copper (having poor mechanical strength) is known as Dezincification [4]. This type of corrosion manifests itself in two general ways:- Uniform or Layer - type Dezincification, and Local or Plug - type. The uniform type seems to be prevalent in alloys of high zinc content, whereas the local or plug - type occurs in alloys of lower zinc content.

The Alpha - Beta structured alloys may undergo a selective type of Dezincification, the Beta grains being de-zincified first. The resistance toward dezincification of Brass changes abruptly at about $80 \% \mathrm{Cu}, 20 \% \mathrm{Zn}$. Brasses ranging in composition from $100 \%$ to $80 \% \mathrm{Cu}$ have very high resistance to dezincification damage. For examples, the use of Red Brass ( $85 \% \mathrm{Cu}, 15 \% \mathrm{Zn}$ ) has eliminated dezincification in plumbing pipe systems. Brasses containing less than $80 \% \mathrm{Cu}$, may de-zincify under corrosive conditions, and Muntz Brass $(60 \% \mathrm{Cu}, 40 \% \mathrm{Zn})$ has the least resistance of the commercial copper - zinc alloy [4].

Corrosion as a chemical change needs a wide knowledge of chemistry, especially in areas of Electrochemistry and Metallurgy. This is so because corrosion is a function of the structure and compositions of the materials (metals). Similarly, from our daily interaction with our environment, we observe that corrosion processes affect our workshop tools, industrial equipment and plants, etc. some of these effects include: (i). Loss of Efficiency:- e.g. Blocking of pipes with rust which needs increasing pumping capacity. (ii). Over Design:- This is common in the designing of reactor, boilers, condenser tubes, much more than the normal standard. (iii). Closure of Industry:- When all the tools and machines have depreciated and become obsolete, it may lead to closure or shut down of industry. (iv). Contamination of Products:This is seen to be versatile in many industries and even in our homes. These contaminations cause health hazards, low quality of products, etc. The poisonous effect of small amounts of lead $(\mathrm{Pb})$ has been known for a long time. In a letter to Benjamin Vaughn, dated July 31, 1786, Benjamin Franklin warned against possible hazards from water collected on lead - roofs, which causes a disease they called "Dry - Belly - Ache" [5].

All the problems listed above require economic consideration. This is because maintenance will adversely run - 
down the economy of a nation, hence the need for specialist in the different industrial set - up, to have knowledge of corrosion science, as to combat this ugly and destructive phenomenon [5]. Pure scientist must have full knowledge of this process as to study / teach the corrosion chemistry and function of a particular metal which can help for technological development. An Engineer needs the knowledge of corrosion processes in their carrier for his designing purposes as to eliminate damages in the reactors and clogging of pipe line. The Health Authorities have needs for the knowledge of corrosion so that much health hazards are reduced to a barely minimum.

Inhibitors are chemical substances that when added in small amounts to the environment in which the metal would corrode, will retard or entirely prevent corrosion. Alternatively, an inhibitor is a substance that when added in small concentrations to an aggressive environment decreases the corrosion rate. Therefore, Corrosion Inhibitors are chemical substances which when added in a small concentration to an aggressive environment effectively decreases corrosion of metals. However, in this work, the term inhibitor is restricted to those materials that must interact with the metal surface to prevent corrosion.

There are basically three types of inhibitors:- (i). Inorganic Inhibitors, (ii). Organic Inhibitors and (iii). Vapour - Phase Inhibitors.

Inorganic Inhibitors:- A sub - classification is usually made on the basis of functioning of the inhibitor with or without oxygen. Inhibitors that can function without oxygen are sometimes called Passivators. These compounds include Chromate and Nitrate. They themselves are readily reduced, and are able to oxidize the metal surface, usually iron, to form a passive oxide film. Other inorganic inhibitors require oxygen. These include Sodium Phosphates, Silicates, and Borates. Inhibitors may also be classified in terms of their mechanism, i.e. whether they function by influencing the Anodic or Cathodic side of the Electrochemical Corrosion Cell, although there is no general agreement with regard to a given inhibitors functioning as an Anodic or Cathodic inhibitors, under all conditions of $\mathrm{pH}$, Oxygen content, and temperature. However, Chromates, Nitrites, Silicates, Phosphates, and Borates are usually considered to be Anodic inhibitors, and those cations that react with the cathodically generated Hydroxide to form an insoluble compound, such as $\mathrm{Mg}^{2+}, \mathrm{Cu}^{2+}, \mathrm{Zn}^{2+}, \mathrm{Cd}^{2+}, \mathrm{Mn}^{2+}$, and $\mathrm{Ni}^{2+}$, are considered to be cathodic inhibitors. The differentiation is made by the direction in which the potential moves upon the addition of the inhibitors to the system. An Anodic inhibitor will cause the potential to move in the positive direction, while the cathodic inhibitor will move the potential in the negative direction, i.e. towards the equilibrium potential of the Anodic reaction.

Organic Inhibitors:- A large number of organic compounds have been used as organic inhibitors. They include Hydrazine, Aniline, 1-phenyl-3-methylpyrazol-5-one, 1phenyl-3-methyl-4-(p-Nitrobenzoyl)-pyrazol-5-one, etc. Their effectiveness depends on the type of bonding they achieve with the metals. For them, to be effective, they must be adsorbed, but the type of adsorption bond varies with the chemical configuration of the organic molecule. The main type of adsorption involves electrostatic adsorption, chemisorptions, and $\pi$-bond (delocalized electron) adsorption. Some of the types of compounds that function through electrostatic adsorption (Aniline, Pyridine, etc) may also function by a chemisorptions process. Chemisorptions is most evident with Nitrogen or Sulphur Heterocycles. The interaction of delocalized electrons ( $\pi$-bond orbital interaction) with the metallic surface may be quite effective. The opportunity for $\pi$-bond interaction with the metal increases as the structure goes from the single to the double to the triple bonds, though such factors as steric interference may decrease the efficiency of inhibition.

Vapour - Phase Inhibitors:- These are very similar to the organic adsorption type inhibitors and possess a very high pressure. As a consequence, these materials can be used to inhibit atmospheric corrosion of metals without being placed in direct contact with the metal surface in use, such inhibitors are placed in the vicinity of the metal to be protected and the condensation to the metal. The Vapour - Phase Inhibitors are usually only effective if used in closed spaces, such as inside packages or on the interior of machinery during shipment

There are numerous inhibitor types and compositions. Most inhibitors have been developed by empirical experimentation and many inhibitors are proprietary in nature and thus their composition is not disclosed. Inhibition is not completely understood because of these reasons, but it is possible to classify inhibitors according to their mechanism and composition. Some inhibitors retard corrosion by adsorption to form an invisible thin film only a few molecules thick, others form visible bulky precipitates which coat the metal and protect it from attack. Another common mechanism consists of causing the metal to corrode in such a way that a combination of adsorption and corrosion products forms a passive layer. But in this present work, the inhibitors used are organic inhibitors which are the adsorption type of inhibitors which adhere to the surface of the metal protecting the metal from further corrosion.

Justification: It has been on the highlight that the importance of protection against corrosion in acidic solutions is increased by the fact that mild steel and related materials, which are more susceptible to be attacked in aggressive media, are the commonly exposed metals in industries and that the use of inhibitors is one of the most practical methods for protection against corrosion especially in acid solutions to prevent metal dissolution, delamination, wear off, and the resultant acid consumption. In this present work, HPMP and its derivative, HPMNP were used for to with the quest of investigating their effectiveness as corrosion inhibitors. Though, there could be few or no much information in the literature about the usefulness and effectiveness of HPMP and HPMNP as corrosion inhibitors as unveiled in this work.

\section{Materials and Methods}


Two samples of Brass were used:-(i). Beta - Brass (60\% $\mathrm{Cu}, 40 \% \mathrm{Zn})$ Coupons of dimensions (13 $\times 3 \times 12 \mathrm{~mm})$ and Alpha-Brass $(70 \% \mathrm{Cu}, 30 \% \mathrm{Zn})$ coupons of dimensions (12 x 2 × $9 \mathrm{~mm}$ ).

In addition to routine laboratory apparatus, the following equipment find usage in this analysis: Desiccators, Beakers, Mettle Analytical Balance, Glass Rods, Glass Hooks, etc.

Reagents include Ethanol, Acetone Hydrochloric acid (concentrations of $0.1 \mathrm{M}, 0.3 \mathrm{M}, 0.5 \mathrm{M}, 0.8 \mathrm{M}$ and $1.0 \mathrm{M}$ ), HPMP and HPMNP (of concentrations of $0.1 \times 10^{-4} \mathrm{M}$, $0.2 \times 10^{-4} \mathrm{M}, 0.5 \times 10^{-4} \mathrm{M}, 1.0 \times 10^{-4} \mathrm{M}, 5.0 \times 10^{-4} \mathrm{~m}, 0.01 \mathrm{M}, 0.02 \mathrm{M}$, $0.03 \mathrm{M}, 0.05 \mathrm{M}$ and $0.08 \mathrm{M}$, prepared in $1.0 \mathrm{M} \mathrm{HCl}$ solution), Distilled, $20 \% \mathrm{HCl}, 20 \%$ Sodium hydroxide, etc.

The coupons were cut out to specific dimensions, mechanically polished to optical flatness, degreased in absolute ethanol, dried in acetone and stored in moisture - free desiccators before their use in this study. The acid medium was Hydrochloric acid. Acid concentrations of $0.1 \mathrm{M}, 0.3 \mathrm{M}$, $0.5 \mathrm{M}, 0.8 \mathrm{M}$ and $1.0 \mathrm{M}$ were prepared and the corrosion of Brass in them was monitored through the weight loss techniques.

The additives used as inhibitors were synthesized, characterized, supplied and utilized as received. Inhibitor concentrations of $0.1 \times 10^{-4} \mathrm{M}, 0.2 \times 10^{-4} \mathrm{M}, 0.5 \times 10^{-4} \mathrm{M}, 1.0 \times 10^{-4} \mathrm{M}$, $5.0 \times 10^{-4} \mathrm{~m}, 0.01 \mathrm{M}, 0.02 \mathrm{M}, 0.03 \mathrm{M}, 0.05 \mathrm{M}$ and $0.08 \mathrm{M}$ were prepared in $1.0 \mathrm{M} \mathrm{HCl}$ solution. Distilled water was used for the preparation of all solutions. The prepared additive solutions were used for all measurements.

Ten $250 \mathrm{ml}$ beakers, which separately contained $0.1,0.3$, $0.5,0.8$ and $1.0 \mathrm{M} \mathrm{HCl}$ solutions, were placed at room temperature $\left(30^{\circ} \mathrm{C}\right)$, thus constituting two sets of experiment for the two different samples of Brass.

The weighed coupons were each suspended in a beaker with the help of glass rods and glass hook. These coupons were retrieved at one day, two days, three days, four days and five days (i.e, progressively for 15 days), each retrieved coupon was scrubbed, brushed and eventually cleaned with $20 \% \mathrm{HCl}$ solution to remove films and corrosion products. It was then washed several times in $20 \%$ Sodium Hydroxide solution, dried in Acetone and reweighed. The weight loss was evaluated in grams. Each reading taken represented the average of two readings recorded on a Mettler Analytical Balance to the nearest $0.0001 \mathrm{~g}$. Further measurements using weight loss determination involved the introduction of the compounds as inhibitors into the two sets of twenty beakers maintained at the same room temperature. Each of the previously weighed Brass coupons was introduced into ten of the twenty beakers containing HPMP and the other ten beakers containing HPMNP. The experiments, in the presence of the additives (HPMP and HPMNP) were performed differently. As described earlier, each couple was retrieved from the corrodent, $\mathrm{HCl}$ - inhibitor (HPMP and HPMNP) solutions at a day, two days, three days, four days and five days for a total period of 15 days, washed and weighed. The difference in weight of the coupons was taken as the weight loss. HPMP and HPMNP were first dissolved in small quantity of Ethanol before it was able to dissolve in the distilled water used to prepare the HCl-HPMP and HClHPMNP solutions of different concentrations.

\section{Results and Discussion}

Results were presented as mean values of triplicate analysis.

Alpha - Brass $(70 \% \mathrm{Cu}, 30 \% \mathrm{Zn})$ and Beta - Brass $(60 \%$ $\mathrm{Cu}, 40 \% \mathrm{Zn}$ ) corroded in the Hydrochloric acid solution. The more active species or phase (Zinc) went into solution faster than the other (Copper). The reactions can be represented by the following chemical equations:

$$
\begin{gathered}
\mathrm{Zn} \rightarrow \mathrm{Zn}^{2+}+2 \mathrm{e} \\
\mathrm{Cu} \rightarrow \mathrm{Cu}^{2+}+2 \mathrm{e} \\
\mathrm{HCl} \rightarrow \mathrm{H}^{+}+\mathrm{Cl}^{-} \\
\mathrm{Zn}^{2+}+2 \mathrm{Cl}^{-} \rightarrow \mathrm{ZnCl}_{2} \\
\mathrm{Cu}^{2+}+2 \mathrm{Cl}^{-} \rightarrow \mathrm{CuCl}_{2}
\end{gathered}
$$

The formation of a blue solution in Hydrochloric acid solution was an indication of the presence of $\mathrm{Cu}^{2+}$ ions. The $\mathrm{CuCl}_{2}$ is a yellow precipitate which was seen on the surfaces of the Brass coupons as corrosion products. The hydrated Copper salt imparted the blue colour found as a corrosion product during the reaction. The change in weight (i.e. weight loss) of the Brass in the different concentrations of Hydrochloric acid solution was followed or monitored, both in the presence and absence of the additives (HPMP and HPMNP). Corrosion rate was found or observed to increase with increase in concentrations of the $\mathrm{HCl}$ solution (as is represented in Tables $1-5$ and Tables $26-30$. Low concentrations of the additives (HPMP and HPMNP) stimulated corrosion (as are represented in Tables $6-15$ and Tables 31 - 40. Similarly, the additives inhibit better at higher concentrations (as are revealed by the Tables $16-25$ and Tables $41-50$. In other words, inhibition rate was found to increase when the concentrations of the additives (HPMP and HPMNP) were increased. By comparison, it was observed that Beta - Brass corroded faster than the Alpha - Brass, and that 1-phenyl-3-methyl-4-(p-Nitrobenzoyl)-pyrazol-5one (HPMNP) is a better inhibitor than 1- phenyl3-methylpyrazol-5-one (HPMP). This can be attributed by the presence of Nitrogen, which has a lone - pair of electrons, which it can use to form a complex on the surface of the metal, thereby preventing the surface reaction of the material with the corrodant.

With reference to the role played by immersion time (for various concentration of $\mathrm{HCl}$ solution), This research strongly agrees with the study on chemical composition and effect of Warionia saharea essential oil on the corrosion of mild steel in $0.5 \mathrm{M} \mathrm{H} 2 \mathrm{SO} 4$ conducted by weight loss measurements [13]. 
Table 1. Variation In Weight for Beta Brass in $0.1 \mathrm{M} \mathrm{HCl} \mathrm{Solution}$

\begin{tabular}{cccccc}
\hline & \multicolumn{5}{c}{ DAYS } \\
\cline { 2 - 6 } & 1 & 2 & 3 & 4 & 5 \\
\hline Initial weight (g) & 3.3366 & 3.3251 & 3.2926 & 3.2444 & 3.2039 \\
New weight (g) & 3.3251 & 3.2926 & 3.2444 & 3.2039 & 3.1502 \\
Weight loss (g) & 0.0115 & 0.0325 & 0.0482 & 0.0405 & 0.0537 \\
\hline
\end{tabular}

Table 2. Variation in weight for Beta Brass in $0.3 \mathrm{M} \mathrm{HCl} \mathrm{Solution}$

\begin{tabular}{lccccc}
\hline & \multicolumn{5}{c}{ DAYS } \\
\cline { 2 - 6 } & 1 & 2 & 3 & 4 & 5 \\
\hline Initial weight $(\mathrm{g})$ & 2.8988 & 2.8888 & 2.8215 & 2.7113 & 2.6099 \\
New weight $(\mathrm{g})$ & 2.8888 & 2.8215 & 2.7113 & 2.6099 & 2.5460 \\
Weight loss $(\mathrm{g})$ & 0.0100 & 0.0673 & 0.1102 & 0.1014 & 0.0639 \\
\hline
\end{tabular}

Table 3. variation in weight for Beta Brass in $0.5 \mathrm{M} \mathrm{HCl}$ solution

\begin{tabular}{lccccc}
\hline & \multicolumn{5}{c}{ DAYS } \\
\cline { 2 - 6 } & 1 & 2 & 3 & 4 & 5 \\
\hline Initial weight $(\mathrm{g})$ & 2.9956 & 2.9895 & 2.9586 & 2.7829 & 2.5436 \\
New weight (g) & 2.9895 & 2.9586 & 2.7829 & 2.5436 & 2.3710 \\
Weight loss (g) & 0.0061 & 0.0309 & 0.1757 & 0.2393 & 0.1726 \\
\hline
\end{tabular}

Table 4. Variation in Weight for Beta Brass in $0.8 \mathrm{M} \mathrm{HCl}$ Solution

\begin{tabular}{cccccc}
\hline & \multicolumn{5}{c}{ DAYS } \\
\cline { 2 - 6 } & 1 & 2 & 3 & 4 & 5 \\
\hline Initial weight $(\mathrm{g})$ & 3.3832 & 3.3688 & 3.2930 & 3.1277 & 2.7682 \\
New weight (g) & 3.3688 & 3.2930 & 3.1277 & 2.7682 & 2.5120 \\
Weight loss (g) & 0.0144 & 0.0758 & 0.1653 & 0.3595 & 0.2562 \\
\hline
\end{tabular}

Table 5. Variation in Weight for Beta Brass in $1.0 \mathrm{M} \mathrm{HCl}$ Solution

\begin{tabular}{lccccc}
\hline & \multicolumn{5}{c}{ DAYS } \\
\cline { 2 - 6 } & 1 & 2 & 3 & 4 & 5 \\
\hline Initial weight (g) & 2.6799 & 2.6652 & 2.5999 & 2.2818 & 1.9560 \\
New weight (g) & 2.6652 & 2.5999 & 2.2818 & 1.9560 & 1.7135 \\
Weight loss (g) & 0.0147 & 0.0653 & 0.3181 & 0.3258 & 0.2425 \\
\hline
\end{tabular}

Table 6. Variation in Weight for Beta Brass in $0.1 \times 10^{-4} \mathrm{M}$ HPMP in $1.0 \mathrm{M}$ $\mathrm{HCl}$ solution

\begin{tabular}{cccccc}
\hline & \multicolumn{5}{c}{ DAYS } \\
\cline { 2 - 6 } & 1 & 2 & 3 & 4 & 5 \\
\hline Initial weight $(\mathrm{g})$ & 2.5120 & 2.4941 & 2.4632 & 2.2945 & 2.0036 \\
New weight $(\mathrm{g})$ & 2.4941 & 2.4632 & 2.2945 & 2.0036 & 1.5812 \\
Weight loss $(\mathrm{g})$ & 0.0179 & 0.0309 & 0.1687 & 0.2909 & 0.3224 \\
\hline
\end{tabular}

Table 7. Variation in Weight for Beta Brass in $0.2 \times 10^{-4} \mathrm{M}$ HPMP in $1.0 \mathrm{M}$ $\mathrm{HCl}$ solution

\begin{tabular}{cccccc}
\hline & \multicolumn{5}{c}{ DAYS } \\
\cline { 2 - 6 } & 1 & 2 & 3 & 4 & 5 \\
\hline Initial weight (g) & 2.3710 & 2.3548 & 2.2868 & 2.0369 & 1.7318 \\
New weight (g) & 2.3548 & 2.2868 & 2.0369 & 1.7318 & 1.5699 \\
Weight loss (g) & 0.0162 & 0.0680 & 0.2499 & 0.3051 & 0.1619 \\
\hline
\end{tabular}

Table 8. Variation in weight for Beta Brass in $0.5 \times 10^{-4} \mathrm{M}$ HPMP in $1.0 \mathrm{M}$ $\mathrm{HCl}$ solution

\begin{tabular}{lccccc}
\hline & \multicolumn{5}{c}{ DAYS } \\
\cline { 2 - 6 } & 1 & 2 & 3 & 4 & 5 \\
\hline Initial weight $(\mathrm{g})$ & 1.7135 & 1.7014 & 1.6721 & 1.5252 & 1.2574 \\
New weight $(\mathrm{g})$ & 1.7014 & 1.6721 & 1.5252 & 1.2574 & 0.9284 \\
Weight loss (g) & 0.0121 & 0.0293 & 0.1469 & 0.2678 & 0.3290 \\
\hline
\end{tabular}

Table 9. Variation in weight for Beta Bass in $1.0 \times 10^{-4} \mathrm{M}$ HPMP in $1.0 \mathrm{M}$ $\mathrm{HCl}$ solution

\begin{tabular}{cccccc}
\hline & \multicolumn{5}{c}{ DAYS } \\
\cline { 2 - 6 } & 1 & 2 & 3 & 4 & 5 \\
\hline Initial weight $(\mathrm{g})$ & 2.5460 & 2.5346 & 2.5090 & 2.3506 & 2.0221 \\
New weight $(\mathrm{g})$ & 2.5346 & 2.5090 & 2.3506 & 2.0221 & 1.7189 \\
Weight loss (g) & 0.0114 & 0.0256 & 0.1584 & 0.3285 & 0.3032 \\
\hline
\end{tabular}

Table 10. Variation in weight for Beta Brass in $5.0 \times 10^{-4} \mathrm{M}$ HPMP in $1.0 \mathrm{M} \mathrm{HCl}$ solution

\begin{tabular}{lccccc}
\hline & \multicolumn{5}{c}{ DAYS } \\
\cline { 2 - 6 } & 1 & 2 & 3 & 4 & 5 \\
\hline Initial weight (g) & 3.1502 & 3.1348 & 3.0826 & 2.8627 & 2.5357 \\
New weight (g) & 3.1348 & 3.0826 & 2.8627 & 2.5357 & 2.3049 \\
Weight loss (g) & 0.0154 & 0.0522 & 0.2199 & 0.3270 & 0.2308 \\
\hline
\end{tabular}

Table 11. Variation in Weight for Beta Brass in $0.1 \times 10^{-4} \mathrm{M}$ HPMNP in $1.0 \mathrm{M} \mathrm{HCl}$ solution

\begin{tabular}{cccccc}
\hline & \multicolumn{5}{c}{ DAYS } \\
\cline { 2 - 6 } & 1 & 2 & 3 & 4 & 5 \\
\hline Initial weight $(\mathrm{g})$ & 4.8828 & 4.8792 & 4.8321 & 4.4735 & 4.1822 \\
New weight $(\mathrm{g})$ & 4.8792 & 4.8321 & 4.4735 & 4.1822 & 3.9592 \\
Weight loss $(\mathrm{g})$ & 0.0036 & 0.0471 & 0.3586 & 0.2913 & 0.2230 \\
\hline
\end{tabular}

Table 12. Variation in weight for Brass in $0.5 \times 10^{-4} \mathrm{M}$ HPMNP in $1.0 \mathrm{M}$ $\mathrm{HCl}$ solution

\begin{tabular}{lccccc}
\hline & \multicolumn{5}{c}{ DAYS } \\
\cline { 2 - 6 } & 1 & 2 & 3 & 4 & 5 \\
\hline Initial weight $(\mathrm{g})$ & 3.0387 & 3.0324 & 3.0204 & 2.9216 & 2.5919 \\
New weight (g) & 3.0324 & 3.0204 & 2.9216 & 2.5919 & 2.1527 \\
Weight loss (g) & 0.0063 & 0.0120 & 0.0988 & 0.3297 & 0.4392 \\
\hline
\end{tabular}

Table 13. Variation in weight for Brass in $0.5 \times 10^{-4} \mathrm{M}$ HPMNP in $1.0 \mathrm{M}$ $\mathrm{HCl}$ solution

\begin{tabular}{cccccc}
\hline & \multicolumn{5}{c}{ DAYS } \\
\cline { 2 - 6 } & 1 & 2 & 3 & 4 & 5 \\
\hline Initial weight $(\mathrm{g})$ & 5.2176 & 5.2131 & 5.1839 & 4.7900 & 4.4509 \\
New weight $(\mathrm{g})$ & 5.2131 & 5.1839 & 4.7900 & 4.4509 & 4.2447 \\
Weight loss $(\mathrm{g})$ & 0.0045 & 0.0292 & 0.3939 & 0.3391 & 0.2062 \\
\hline
\end{tabular}

Table 14. Variation in weight for Beta Brass in $1.0 \times 10^{-4} \mathrm{M}$ HPMNP in $1.0 \mathrm{M} \mathrm{HCl}$ Solution

\begin{tabular}{cccccc}
\hline & \multicolumn{5}{c}{ DAY } \\
\cline { 2 - 6 } & 1 & 2 & 3 & 4 & 5 \\
\hline initial weight $(\mathrm{g})$ & 4.0777 & 4.0749 & 4.0543 & 3.8318 & 3.4607 \\
New weight $(\mathrm{g})$ & 4.0749 & 4.0543 & 3.8318 & 3.4607 & 3.2018 \\
weight loss $(\mathrm{g})$ & 0.0028 & 0.0206 & 0.2225 & 0.3711 & 0.2589 \\
\hline
\end{tabular}

Table 15. Variation in weight for Beta Brass in $5.0 \times 10^{-4} \mathrm{M}$ HPMNP in 1.0M HCl solution

\begin{tabular}{lccccc}
\hline & \multicolumn{5}{c}{ DAYS } \\
\cline { 2 - 6 } & 1 & 2 & 3 & 4 & 5 \\
\hline Initial weight $(\mathrm{g})$ & 3.9941 & 3.9912 & 3.9701 & 3.7485 & 3.3827 \\
New weight (g) & 3.9912 & 3.9701 & 3.7485 & 3.3827 & 3.0918 \\
Weight loss (g) & 0.0029 & 0.0211 & 0.2216 & 0.3658 & 0.2909 \\
\hline
\end{tabular}

Table 16. Variation in weight for Beta Brass in 0.01M HPMP in $1.0 \mathrm{M} \mathrm{HCl}$ solution

\begin{tabular}{lccccc}
\hline & \multicolumn{5}{c}{ DAYS } \\
\cline { 2 - 6 } & 1 & 2 & 3 & 4 & 5 \\
\hline Initial weight $(\mathrm{g})$ & 1.5497 & 1.5367 & 1.5218 & 1.4714 & 1.1422 \\
New weight $(\mathrm{g})$ & 1.5367 & 1.5218 & 1.4714 & 1.1422 & 0.9021 \\
Weight loss $(\mathrm{g})$ & 0.0130 & 0.0149 & 0.0504 & 0.3292 & 0.2401 \\
\hline
\end{tabular}


Table 17. Variation in weight for Beta Brass in $0.02 \mathrm{M}$ HPMP in $1.0 \mathrm{M} \mathrm{HC}$ solution

\begin{tabular}{cccccc}
\hline & \multicolumn{5}{c}{ DAYS } \\
\cline { 2 - 6 } & 1 & 2 & 3 & 4 & 5 \\
\hline Initial weight (g) & 2.2874 & 2.2769 & 2.2630 & 2.2216 & 2.0394 \\
New weight (g) & 2.2769 & 2.2630 & 2.2216 & 2.0394 & 1.7946 \\
Weight loss (g) & 0.0105 & 0.0139 & 0.0414 & 0.1822 & 0.2448 \\
\hline
\end{tabular}

Table 18. Variation in weight for Beta Brass in $0.03 \mathrm{M}$ HPMP in $1.0 \mathrm{M}$ $\mathrm{HCl}$ solution

\begin{tabular}{cccccc}
\hline & \multicolumn{5}{c}{ DAYS } \\
\cline { 2 - 6 } & 1 & 2 & 3 & 4 & 5 \\
\hline Initial weight $(\mathrm{g})$ & 1.7008 & 1.6938 & 1.6907 & 1.6834 & 1.6704 \\
New weight $(\mathrm{g})$ & 1.6938 & 1.6907 & 1.6834 & 1.6704 & 1.6459 \\
Weight loss (g) & 0.0070 & 0.0031 & 0.0073 & 0.0130 & 0.0245 \\
\hline
\end{tabular}

Table 19. Variation in weight for Beta - Brass in $0.05 \mathrm{M}$ HPMP in $1.0 \mathrm{M}$ $\mathrm{HCl}$ solution

\begin{tabular}{cccccc}
\hline & \multicolumn{5}{c}{ DAYS } \\
\cline { 2 - 6 } & 1 & 2 & 3 & 4 & 5 \\
\hline Initial weight (g) & 1.6674 & 1.6620 & 1.6587 & 1.6524 & 1.6353 \\
New weight (g) & 1.6620 & 1.6587 & 1.6524 & 1.6353 & 1.5899 \\
Weight loss (g) & 0.0054 & 0.0033 & 0.0063 & 0.0171 & 0.0454 \\
\hline
\end{tabular}

Table 20. Variation in weight for Beta - Brass in 0.08M HPMP in $1.0 \mathrm{M}$ $\mathrm{HCl}$ solution

\begin{tabular}{cccccc}
\hline & \multicolumn{5}{c}{ DAYS } \\
\cline { 2 - 6 } & 1 & 2 & 3 & 4 & 5 \\
\hline Initial weight (g) & 0.9197 & 0.9170 & 0.9152 & 0.9119 & 0.9067 \\
New weight (g) & 0.9170 & 0.9152 & 0.9119 & 0.9067 & 0.8971 \\
Weight loss (g) & 0.0027 & 0.0018 & 0.0033 & 0.0052 & 0.0096 \\
\hline
\end{tabular}

Table 21. Variation in weight for Beta- Brass in 0.01M HPMNP in $1.0 \mathrm{M}$ $\mathrm{HCl}$ solution

\begin{tabular}{lccccc}
\hline & \multicolumn{5}{c}{ DAYS } \\
\cline { 2 - 6 } & 1 & 2 & 3 & 4 & 5 \\
\hline Initial weight (g) & 3.9592 & 3.9377 & 3.9209 & 3.8677 & 3.6558 \\
New weight (g) & 3.9377 & 3.9209 & 3.8677 & 3.6558 & 3.4316 \\
Weight loss (g) & 0.0215 & 0.0168 & 0.0532 & 0.2119 & 0.2242 \\
\hline
\end{tabular}

Table 22. Variation in weight for Beta - Brass in 0.02M HPMNP in 1.0M $\mathrm{HCl}$ solution

\begin{tabular}{lccccc}
\hline & \multicolumn{5}{c}{ DAYS } \\
\cline { 2 - 6 } & 1 & 2 & 3 & 4 & 5 \\
\hline Initial weight $(\mathrm{g})$ & 2.1527 & 2.1448 & 2.1361 & 2.1250 & 2.1025 \\
New weight $(\mathrm{g})$ & 2.1448 & 2.1361 & 2.1250 & 2.1025 & 2.0605 \\
Weight loss (g) & 0.0079 & 0.0087 & 0.0111 & 0.0225 & 0.0420 \\
\hline
\end{tabular}

Table 23. Variation in weight for Beta- Brass in 0.03M HPMNP in 1.0M $\mathrm{HCl}$ solution

\begin{tabular}{cccccc}
\hline & \multicolumn{5}{c}{ DAYS } \\
\cline { 2 - 6 } & 1 & 2 & 3 & 4 & 5 \\
\hline Initial weight $(\mathrm{g})$ & 4.2447 & 4.2317 & 4.2220 & 4.2020 & 4.1347 \\
New weight $(\mathrm{g})$ & 4.2317 & 4.2220 & 4.2020 & 4.1347 & 3.9190 \\
Weight loss (g) & 0.0130 & 0.0097 & 0.0200 & 0.0673 & 0.2157 \\
\hline
\end{tabular}

Table 24. Variation in weight for Beta- Brass in 0.05M HPMNP in $1.0 \mathrm{M}$ $\mathrm{HCl}$ solution

\begin{tabular}{|c|c|c|c|c|c|}
\hline & \multicolumn{3}{|c|}{ DAYS } & \multirow[b]{2}{*}{4} & \multirow[b]{2}{*}{5} \\
\hline & 1 & 2 & 3 & & \\
\hline Initial weight (g) & 3.2018 & 3.1925 & 3.1824 & 3.1664 & 3.1240 \\
\hline New weight (g) & 3.1925 & 3.1824 & 3.1664 & 3.1240 & 2.9244 \\
\hline Weight loss (g) & 0.0093 & 0.0101 & 0.0160 & 0.0424 & 0.1996 \\
\hline
\end{tabular}

Table 25. Variation in weight for Beta - Brass in 0.08M HPMNP in $1.0 \mathrm{M}$ $\mathrm{HCl}$ solution

\begin{tabular}{cccccc}
\hline & \multicolumn{5}{c}{ DAYS } \\
\cline { 2 - 6 } & 1 & 2 & 3 & 4 & 5 \\
\hline Initial weight $(\mathrm{g})$ & 3.0918 & 3.0815 & 3.0729 & 3.0599 & 3.0364 \\
New weight $(\mathrm{g})$ & 3.0815 & 3.0729 & 3.0599 & 3.0364 & 2.9720 \\
Weight loss $(\mathrm{g})$ & 0.0103 & 0.0086 & 0.0130 & 0.0235 & 0.0644 \\
\hline
\end{tabular}

Table 26. Variation in weight for Alpha - Brass in $0.1 \mathrm{M} \mathrm{HCl}$ solution

\begin{tabular}{lccccc}
\hline & \multicolumn{5}{c}{ DAYS } \\
\cline { 2 - 6 } & 1 & 2 & 3 & 4 & 5 \\
\hline Initial weight (g) & 3.0642 & 3.0530 & 3.0153 & 2.9698 & 2.9198 \\
New weight (g) & 3.0530 & 3.0153 & 2.9698 & 2.9198 & 2.8502 \\
Weight loss (g) & 0.0112 & 0.0377 & 0.0455 & 0.0500 & 0.0696 \\
\hline
\end{tabular}

Table 27. Variation in weight for Alpha - Brass in $0.3 \mathrm{M} \mathrm{HCl}$ solution

\begin{tabular}{cccccc}
\hline & \multicolumn{5}{c}{ DAYS } \\
\cline { 2 - 6 } & 1 & 2 & 3 & 4 & 5 \\
\hline Initial weight $(\mathrm{g})$ & 2.4331 & 2.4243 & 2.3511 & 2.2328 & 2.1301 \\
New weight $(\mathrm{g})$ & 2.4243 & 2.3511 & 2.2328 & 2.1301 & 2.0262 \\
Weight loss (g) & 0.0088 & 0.0732 & 0.1183 & 0.1027 & 0.1039 \\
\hline
\end{tabular}

Table 28. Variation in weight for Alpha - Brass in $0.5 \mathrm{M} \mathrm{HCl}$ solution

\begin{tabular}{cccccc}
\hline & \multicolumn{5}{c}{ DAYS } \\
\cline { 2 - 6 } & 1 & 2 & 3 & 4 & 5 \\
\hline Initial weight $(\mathrm{g})$ & 2.3893 & 2.3741 & 2.2535 & 2.0443 & 1.8544 \\
New weight $(\mathrm{g})$ & 2.3741 & 2.2535 & 2.0443 & 1.8544 & 1.7393 \\
Weight loss (g) & 0.0152 & 0.1206 & 0.2092 & 0.1899 & 0.1151 \\
\hline
\end{tabular}

Table 29. Variation in weight for Alpha - Brass in $0.8 \mathrm{M} \mathrm{HCl}$ solution

\begin{tabular}{cccccc}
\hline & \multicolumn{5}{c}{ DAYS } \\
\cline { 2 - 6 } & 1 & 2 & 3 & 4 & 5 \\
\hline Initial weight $(\mathrm{g})$ & 1.8415 & 1.8289 & 1.7400 & 1.4529 & 1.1608 \\
New weight $(\mathrm{g})$ & 1.8289 & 1.7400 & 1.4529 & 1.1608 & 0.9837 \\
Weight loss (g) & 0.0126 & 0.0889 & 0.2871 & 0.2921 & 0.1771 \\
\hline
\end{tabular}

Table 30. Variation in weight for Alpha- Brass in $1.0 \mathrm{M} \mathrm{HCl}$ solution

\begin{tabular}{cccccc}
\hline & \multicolumn{5}{c}{ DAYS } \\
\cline { 2 - 6 } & 1 & 2 & 3 & 4 & 5 \\
\hline Initial weight $(\mathrm{g})$ & 2.5216 & 2.5114 & 2.3895 & 2.0248 & 1.6932 \\
New weight $(\mathrm{g})$ & 2.5114 & 2.3895 & 2.0243 & 1.6932 & 1.4152 \\
Weight loss (g) & 0.0102 & 0.1219 & 0.3642 & 0.3316 & 0.2780 \\
\hline
\end{tabular}

Table 31. Variation in weight for Alpha - Brass in $0.1 \times 10^{-4} \mathrm{M}$ HPMP in $1.0 \mathrm{M} \mathrm{HCl}$ solution

\begin{tabular}{lccccc}
\hline & \multicolumn{5}{c}{ DAYS } \\
\cline { 2 - 6 } & 1 & 2 & 3 & 4 & 5 \\
\hline Initial weight (g) & 0.9837 & 0.9658 & 0.9459 & 0.8148 & 0.5892 \\
New weight (g) & 0.9658 & 0.9459 & 0.8148 & 0.5892 & 0.3982 \\
Weight loss (g) & 0.0179 & 0.0199 & 0.1311 & 0.2256 & 0.1910 \\
\hline
\end{tabular}

Table 32. Variation in weight for Alpha - Brass in $0.2 \times 10^{-4} \mathrm{M}$ HPMP in 1.0M HCl solution

\begin{tabular}{cccccc}
\hline & \multicolumn{5}{c}{ DAYS } \\
\cline { 2 - 6 } & 1 & 2 & 3 & 4 & 5 \\
\hline Initial weight (g) & 1.4152 & 1.3982 & 1.3723 & 1.1684 & 0.9325 \\
New weight (g) & 1.3982 & 1.3723 & 1.1684 & 0.9325 & 0.7245 \\
Weight loss (g) & 0.0170 & 0.0259 & 0.2039 & 0.2359 & 0.2080 \\
\hline
\end{tabular}


Table 33. Variation in weight for Alpha - Brass in $0.5 \times 10^{-4} \mathrm{M}$ HPMP in $1.0 \mathrm{M} \mathrm{HCl}$ solution

\begin{tabular}{cccccc}
\hline & \multicolumn{5}{c}{ DAYS } \\
\cline { 2 - 6 } & 1 & 2 & 3 & 4 & 5 \\
\hline Initial weight (g) & 1.7393 & 1.7170 & 1.6746 & 1.4447 & 1.2097 \\
New weight (g) & 1.7170 & 1.6746 & 1.4447 & 1.2097 & 1.0089 \\
Weight loss (g) & 0.0223 & 0.0424 & 0.2299 & 0.2350 & 0.2008 \\
\hline
\end{tabular}

Table 34. Variation in weight for Alpha - Brass in $1.0 \times 10^{-4} \mathrm{M}$ HPMP in $1.0 \mathrm{M} \mathrm{HCl}$ solution

\begin{tabular}{cccccc}
\hline & \multicolumn{5}{c}{ DAYS } \\
\cline { 2 - 6 } & 1 & 2 & 3 & 4 & 5 \\
\hline Initial weight (g) & 2.8502 & 2.8298 & 2.7498 & 2.4598 & 2.1755 \\
New weight (g) & 2.8298 & 2.7498 & 2.4598 & 2.1755 & 2.0422 \\
Weight loss (g) & 0.0204 & 0.0800 & 0.2900 & 0.2843 & 0.1333 \\
\hline
\end{tabular}

Table 35. Variation in weight for Alpha - Brass in $5.0 \times 10^{-4} \mathrm{M}$ HPMP in $1.0 \mathrm{M} \mathrm{HCl}$ solution

\begin{tabular}{cccccc}
\hline & \multicolumn{5}{c}{ DAYS } \\
\cline { 2 - 6 } & 1 & 2 & 3 & 4 & 5 \\
\hline Initial weight (g) & 2.0262 & 2.0039 & 1.9493 & 1.6701 & 1.3869 \\
New weight (g) & 2.0039 & 1.9493 & 1.6701 & 1.3869 & 1.2180 \\
Weight loss (g) & 0.0223 & 0.0546 & 0.2792 & 0.2832 & 0.1689 \\
\hline
\end{tabular}

Table 36. Variation in weight for Alpha - Brass in $0.1 \times 10^{-4} \mathrm{M}$ HPMNP in $1.0 \mathrm{M} \mathrm{HCl}$ solution

\begin{tabular}{|c|c|c|c|c|c|}
\hline & \multicolumn{3}{|c|}{ DAYS } & \multirow[b]{2}{*}{4} & \multirow[b]{2}{*}{5} \\
\hline & 1 & 2 & 3 & & \\
\hline Initial weight (g) & 2.7539 & 2.7507 & 2.7513 & 2.4850 & 2.1193 \\
\hline New weight (g) & 2.7507 & 2.7313 & 2.4850 & 2.1193 & 1.7693 \\
\hline Weight loss $(\mathrm{g})$ & 0.0032 & 0.0194 & 0.2463 & 0.3657 & 0.3500 \\
\hline
\end{tabular}

Table 37. Variation in weight for Alpha- Brass in $0.2 \times 10^{-4} \mathrm{M}$ HPMNP in $1.0 \mathrm{M} \mathrm{HCl}$ solution

\begin{tabular}{cccccc}
\hline & \multicolumn{5}{c}{ DAYS } \\
\cline { 2 - 6 } & 1 & 2 & 3 & 4 & 5 \\
\hline Initial weight $(\mathrm{g})$ & 2.8226 & 2.8181 & 2.7955 & 2.4333 & 2.0188 \\
New weight $(\mathrm{g})$ & 2.8181 & 2.7955 & 2.4333 & 2.0188 & 1.5694 \\
Weight loss $(\mathrm{g})$ & 0.0045 & 0.0226 & 0.3622 & 0.4145 & 0.4494 \\
\hline
\end{tabular}

Table 38. Variation in weight for Alpha- Brass in $0.5 \times 10^{-4} \mathrm{M}$ HPMNP in $1.0 \mathrm{M} \mathrm{HCl}$ solution

\begin{tabular}{cccccc}
\hline & \multicolumn{5}{c}{ DAYS } \\
\cline { 2 - 6 } & 1 & 2 & 3 & 4 & 5 \\
\hline Initial weight $(\mathrm{g})$ & 2.8782 & 2.8740 & 2.8393 & 2.5112 & 2.1357 \\
New weight $(\mathrm{g})$ & 2.8740 & 2.8393 & 2.5112 & 2.1357 & 1.7845 \\
Weight loss (g) & 0.0042 & 0.0347 & 0.3281 & 0.3755 & 0.3512 \\
\hline
\end{tabular}

Table 39. Variation in weight for Alpha- Brass in $1.0 \times 10^{-4} \mathrm{M}$ HPMNP in $1.0 \mathrm{M} \mathrm{HCl}$ solution

\begin{tabular}{cccccc}
\hline & \multicolumn{5}{c}{ DAYS } \\
\cline { 2 - 6 } & 1 & 2 & 3 & 4 & 5 \\
\hline Initial weight $(\mathrm{g})$ & 3.0123 & 3.0074 & 3.0003 & 2.6415 & 2.3260 \\
New weight $(\mathrm{g})$ & 3.0074 & 3.0003 & 2.6415 & 2.3260 & 2.0466 \\
Weight loss $(\mathrm{g})$ & 0.0049 & 0.0071 & 0.3588 & 0.3155 & 0.2794 \\
\hline
\end{tabular}

Table 40. Variation in weight for Alpha - Brass in $5.0 \times 10^{-4} \mathrm{M}$ HPMNP in $1.0 \mathrm{M} \mathrm{HCl}$ solution

\begin{tabular}{cccccc}
\hline & \multicolumn{5}{c}{ DAYS } \\
\cline { 2 - 6 } & 1 & 2 & 3 & 4 & 5 \\
\hline Initial weight $(\mathrm{g})$ & 2.9138 & 2.9064 & 2.8623 & 2.4762 & 2.0848 \\
New weight $(\mathrm{g})$ & 2.9064 & 2.8623 & 2.4762 & 2.0848 & 1.7306 \\
Weight loss $(\mathrm{g})$ & 0.0074 & 0.0441 & 0.3861 & 0.3914 & 0.3542 \\
\hline
\end{tabular}

Table 41. Variation in weight for Alpha- Brass in 0.01M HPMP in $1.0 \mathrm{M}$ $\mathrm{HCl}$ solution

\begin{tabular}{cccccc}
\hline & \multicolumn{5}{c}{ DAYS } \\
\cline { 2 - 6 } & 1 & 2 & 3 & 4 & 5 \\
\hline Initial weight & 1.9873 & 1.9669 & 1.9364 & 1.7808 & 1.5398 \\
New weight & 1.9669 & 0.9364 & 1.7808 & 1.5898 & 1.7655 \\
Weight loss & 0.0204 & 0.0305 & 0.1556 & 0.2410 & 0.2743 \\
\hline
\end{tabular}

Table 42. Variation in weight for Alpha - Brass in 0.02M HPMP in 1.0M $\mathrm{HCl}$ solution

\begin{tabular}{lccccc}
\hline & \multicolumn{5}{c}{ DAYS } \\
\cline { 2 - 6 } & 1 & 2 & 3 & 4 & 5 \\
\hline Initial weight $(\mathrm{g})$ & 1.1716 & 1.1589 & 1.1485 & 1.0711 & 0.8674 \\
New weight $(\mathrm{g})$ & 1.1589 & 1.1485 & 1.0711 & 0.8674 & 0.7034 \\
Weight loss $(\mathrm{g})$ & 0.0127 & 0.0104 & 0.0774 & 0.2037 & 0.1640 \\
\hline
\end{tabular}

Table 43. Variation in weight for Alpha-Brass in 0.03M HPMP in 1.0M $\mathrm{HCl}$ solution

\begin{tabular}{cccccc}
\hline & \multicolumn{5}{c}{ DAYS } \\
\cline { 2 - 6 } & 1 & 2 & 3 & 4 & 5 \\
\hline Initial weight (g) & 0.6917 & 0.6805 & 0.6734 & 0.6621 & 0.6091 \\
New weight (g) & 0.6805 & 0.6734 & 0.6621 & 0.6091 & 0.4191 \\
Weight loss (g) & 0.0112 & 0.0071 & 0.0113 & 0.0530 & 0.1900 \\
\hline
\end{tabular}

Table 44. Variation in weight for Alpha - Brass in 0.05M HPMP in 1.0M $\mathrm{HCl}$ solution

\begin{tabular}{cccccc}
\hline & \multicolumn{5}{c}{ DAYS } \\
\cline { 2 - 6 } & 1 & 2 & 3 & 4 & 5 \\
\hline Initial weight $(\mathrm{g})$ & 0.3557 & 0.3470 & 0.3359 & 0.3246 & 0.2820 \\
New weight $(\mathrm{g})$ & 0.3470 & 0.3359 & 0.3246 & 0.2820 & 0.1250 \\
Weight loss $(\mathrm{g})$ & 0.0087 & 0.0111 & 0.113 & 0.0426 & 0.1570 \\
\hline
\end{tabular}

Table 45. Variation in weight for Alpha- Brass in 0.08M HPMP in $1.0 \mathrm{M}$ $\mathrm{HCl}$ solution

\begin{tabular}{cccccc}
\hline & \multicolumn{5}{c}{ DAYS } \\
\cline { 2 - 6 } & 1 & 2 & 3 & 4 & 5 \\
\hline Initial weight $(\mathrm{g})$ & 0.9318 & 0.9077 & 0.9004 & 0.8861 & 0.8338 \\
New weight (g) & 0.9077 & 0.9004 & 0.8861 & 0.8338 & 0.6932 \\
Weight loss (g) & 0.0241 & 0.0073 & 0.0143 & 0.0523 & 0.1406 \\
\hline
\end{tabular}

Table 46. Variation in weight for Alpha - Brass in 0.01M HPMNP in $1.0 \mathrm{M} \mathrm{HCl}$ solution

\begin{tabular}{cccccc}
\hline & \multicolumn{5}{c}{ DAYS } \\
\cline { 2 - 6 } & 1 & 2 & 3 & 4 & 5 \\
\hline Initial weight $(\mathrm{g})$ & 1.7693 & 1.7513 & 1.7341 & 1.6944 & 1.5499 \\
New weight $(\mathrm{g})$ & 1.7513 & 1.7340 & 1.5944 & 1.5499 & 1.4135 \\
Weight loss $(\mathrm{g})$ & 0.0180 & 0.0173 & 0.0396 & 0.1445 & 0.1364 \\
\hline
\end{tabular}

Table 47. Variation in weight for Alpha - Brass in 0.02M HPMNP in $1.0 \mathrm{M} \mathrm{HCl}$ solution

\begin{tabular}{cccccc}
\hline & \multicolumn{5}{c}{ DAYS } \\
\cline { 2 - 6 } & 1 & 2 & 3 & 4 & 5 \\
\hline Initial weight & 1.5694 & 1.5458 & 1.5316 & 1.5025 & 1.3471 \\
New weight & 1.5458 & 1.5316 & 1.5025 & 1.3471 & 1.0795 \\
Weight loss & 0.0236 & 0.0142 & 0.0291 & 0.1554 & 0.2676 \\
\hline
\end{tabular}

Table 48. Variation in weight for Alpha - Brass in 0.03M HPMNP in 1.0M HCl solution

\begin{tabular}{cccccc}
\hline & \multicolumn{5}{c}{ DAYS } \\
\cline { 2 - 6 } & 1 & 2 & 3 & 4 & 5 \\
\hline Initial weight (g) & 1.7845 & 1.7682 & 1.7596 & 1.7420 & 1.6902 \\
New weight (g) & 1.7682 & 1.7596 & 1.7420 & 1.6902 & 1.5080 \\
Weight loss (g) & 0.0163 & 0.0086 & 0.0176 & 0.0518 & 0.1822 \\
\hline
\end{tabular}


Table 49. Variation in weight for Alpha - Brass in 0.05M HPMNP in 1.0M HCl solution

\begin{tabular}{cccccc}
\hline & \multicolumn{5}{c}{ DAYS } \\
\cline { 2 - 6 } & 1 & 2 & 3 & 4 & 5 \\
\hline Initial weight $(\mathrm{g})$ & 2.0466 & 2.0231 & 1.9946 & 1.9323 & 1.7163 \\
New weight $(\mathrm{g})$ & 2.0231 & 1.9946 & 1.9323 & 1.7163 & 1.5319 \\
Weight loss (g) & 0.0235 & 0.0285 & 0.0623 & 0.2160 & 0.1844 \\
\hline
\end{tabular}

Table 50. Variation in weight for Alpha - Brass in 0.08M HPMNP in $1.0 \mathrm{M} \mathrm{HCl}$ solution

\begin{tabular}{lccccc}
\hline & \multicolumn{5}{c}{ DAYS } \\
\cline { 2 - 6 } & 1 & 2 & 3 & 4 & 5 \\
\hline Initial weight $(\mathrm{g})$ & 1.7306 & 1.7182 & 1.7104 & 1.6976 & 1.6659 \\
New weight $(\mathrm{g})$ & 1.7182 & 1.7104 & 1.6976 & 1.6659 & 1.5719 \\
Weight loss (g) & 0.0124 & 0.0078 & 0.0128 & 0.0317 & 0.0940 \\
\hline
\end{tabular}

\section{Conclusions}

The weight loss method coupled with concentration and immersion time interplay are critical in corrosion monitoring method, and it gives a good estimate of the extent of corrosion. The corrosion inhibitions by HPMP and HPMNP have been attributed to efficient barrier layer formation on the surface of the Brass. HPMP and HPMNP became corrosion accelerators at very low concentrations because the concentration of the additives (inhibitors) was low, which was not sufficient enough to cover or form the protective film on the whole surface of the Brass coupon immersed in the acid inhibitor mixture to protect it from corrosion. The uncovered area was attacked and the film - protected area, which was not strong enough, was affected, thus leading to washing away of this protective film and exposed the metal to continue corroding. Unveiled in this research is the fact that HPMNP is a better inhibitor than HPMP.

\section{ACKNOWLEDGEMENTS}

Authors are grateful to the supplier of the inhibitors and to all authors whose names are referenced in this work.

\section{REFERENCES}

[1] U. J. Ekpe, U.J. Ibok, B.I. Ita, O.E. Offiong and E.E. Ebenso; Inhibitory Action of Methyl and phenyl Thiosemicarbazone derivatives on the corrosion of Mild Steel in Hydrochloric acid, (1994), p. $87-89$.

[2] Swearingen, L.E. and Schram, A.F., J.phys. chem., Ithaca, 55, 180, (1951).

[3] Fontana, M.G.; Corrosion Engineering, 1986, are coition, MC Crawahill, New York, p. 9, 282 - 283, 296.

[4] Fontana, M.G.; Corrosion and Anti - Corrosives; Corrosion Engineering (1986), p. 36 - 39, $290-301,378-383$.

[5] Benjamin Franklin; Auto Biological Writings Edited by Carl van Doren; 1945, Viking Press, p.671.

[6] Evans, U.R.; An introduction to metallic Corrosion; $3^{\text {rd }}$ edition, p.201.

[7] Ogwuegbu, Oforka, and Spiff; solvent extraction of Iron; June, 1994; Discovering and Innovation; Vol. 6, No. 2, p.158.

[8] Ogwuegbu, M.O.C.; Studies on solvent extraction behavior of Iron (iii), Copper (ii), Nickel (ii), and Cobalt (ii), using 1-phenyl-3-methyl-4-(p-Nitrobenzoyl)-pyrazol-1-5-one in various organic diluents; 1991, p. $107-108,5-6,10,61$, 229.

[9] Encyclopedia of Chemical Technology; $3^{\text {rd }}$ edition vo1.7, $\mathrm{p}$. $39-67$.

[10] Encyclopedia of Chemical Technology; $3^{\text {rd }}$ edition vo1.6; $\mathrm{p}$. $213-141$

[11] Badran, B.N., Ardelfattan. A.A., and Abdul Azim, A.A.; corrosion science vo1.22, 1982; p.813-889.

[12] Pollard, W.R., and Lawson, J.V.; Industrial Engineering Chemistry, vo1.39, 1947, p.910.

[13] Znini,M., Majidi L, Laghchimi,A., Paolini,J. Hammouti,B. Costa,J., Bouyanzer,A. and Al-Deyab, S.(2011). Chemical Composition and Anticorrosive Activity of Warionia Saharea Essential Oil Against the Corrosion of Mild Steel In 0.5 M $\mathrm{H}_{2}$ SO4. Int. J. Electrochem. Sci., Vol.6: 5940 - 5955 